\title{
Produção de lipase de Aspergillus niger e imobilização em membranas de poliétersulfona
}

\author{
Fernanda Martins de souza ${ }^{1 *}$, Beatriz Medeiros Travália ${ }^{1}$, Álvaro Silva Lima², \\ Cleide Mara Faria Soares ${ }^{2}$, Luciana Cristina Lins de Aquino Santana ${ }^{1}$ \\ ${ }^{1}$ Programa de Pós-Graduação em Ciência e Tecnologia de Alimentos- Universidade Federal de Sergipe \\ CEP 49100-000 São Cristovão - Sergipe - *E-mail: nandaxca@hotmail.com \\ ${ }^{2}$ Instituto de Tecnologia e Pesquisa (ITP), Universidade Tiradentes (UNIT), Aracaju, Sergipe
}

\begin{abstract}
RESUMO
Uma das formas de aproveitamento de resíduos agroindustriais tem sido a produção de enzimas de interesse industrial, dentre elas podemos destacar as lipases, enzimas de grande importância fisiológica na metabolização de lipídeos, as quais podem ser produzidas por fermentação em estado sólido. A lipase foi produzida por fermentação em estado sólido da farinha de semente de mangaba, posteriormente imobilizada por ligação covalente para avaliação do efeito do pH. A maior atividade enzimática obtida foi de $244,98 \mathrm{U} / \mathrm{g} \mathrm{em} 168 \mathrm{~h}$ de fermentação e o rendimento de imobilização foi de $80 \%$. As enzimas livre e imobilizada apresentaram máxima atividade relativa em pH 6,0. A imobilização de enzimas tem um importante papel dentro da biotecnologia aplicada, pois a aplicação de enzimas como biocatalizadores está normalmente limitada pela falta de estabilidade nas condições operacionais do processo.
\end{abstract}

Palavras-chave: resíduo, enzima, imobilização, fermentação

\section{NTRODUÇÃO}

Enzimas lipolíticas provenientes de micro-organismos apresentam um grande valor para aplicação biotecnológica, devido principalmente a versatilidade de suas propriedades e facilidade de produção em grande escala, sendo um dos grupos mais utilizados no setor industrial (MILETIC et al., 2012). Entretanto, do ponto de vista de aplicação industrial, as lipases na forma livre não podem ser reutilizadas, não sendo economicamente viáveis em alguns processos devido a necessidade de grandes quantidades de enzima.

Neste contexto, o processo de imobilização surgiu para melhorar propriedades enzimáticas como seletividade e estabilidade (MATEO et al., 2007). A ligação ao suporte pode ser física (interação hidrofóbica, van der Waals e interações iônicas) ou de natureza covalente. Na ligação física a enzima é ligada a um suporte por interação hidrofóbica, força de van der Waals ou interações iônicas. A ligação covalente é o método mais utilizado onde a enzima é ligada covalentemente a um suporte quimicamente modificado (LOOS et al., 2011). A principal vantagem deste método é a maior resistência do biocatalisador quanto à variação de pH, temperatura e frente a solventes orgânicos (MENDES et al., 2011).

Uma grande variedade de suportes tem sido utilizada para a imobilização de enzimas, dentre os quais estão as membranas poliméricas. As membranas oferecem como vantagem elevada área superficial para o carregamento de enzimas. Além disso, podem ser derivatizadas e há a possibilidade de separação do produto, nos casos em que o produto inibe a reação (VISHWANATH et al., 1995). Nos últimos anos, alguns pesquisadores têm

Universidade Estadual de Londrina - Rodovia Celso Garcia Cid, Pr 445, Km 380 - Campus Universitário Caixa Postal 10.011 CEP 86057-970 Centro de Ciências Exatas - Departamento de Bioquímica e Biotecnologia Fone +55 (43) 3371.4270 - biq@uel.br 
imobilizado lipases em membranas poliméricas de polisulfona, poliétersulfona (GUPTA et al., 2008), celulose (LU; HSIEG, 2009), membranas de poli (2-hydroxietilmetacrilato-cometacrilamido-fenilalanina) (BAYRAMOGLU et al., 2002), polipropileno (PUJ ARI et al., 2006), quitosana (HUANG et al., 2007) e membranas de álcool polivinílico (WANG; HSIEH, 2008). Contudo, este trabalho objetivou a produção de lipase de Aspergillus niger a partir da fermentação em estado sólido de resíduo de mangaba e posterior imobilização em membranas de poliétersulfona por ligação covalente.

\section{MATERI AI S E MÉTODOS}

O resíduo de mangaba foi obtido após o processamento de polpas de mangaba cedido pela empresa Pomar, localizada na cidade de Aracaju, SE. As sementes de mangaba foram lavadas, secas em secador, Pardal - PE 100, à temperatura de $60{ }^{\circ} \mathrm{C}$ por 8 horas, em seguida, trituradas em moinho tipo Wiley e esterilizadas em autoclave à $121^{\circ} \mathrm{C}$ durante 15 min. As fermentações foram realizadas em placas de petri contendo $10 \mathrm{~g}$ de farinha de sementes de mangaba variando-se a umidade do resíduo ( $50 \%$ e $70 \%$ ) e $10^{6}$ esporos de Aspergillus niger/g de resíduo. As placas foram incubadas à $37^{\circ} \mathrm{C}$ e a cada $24 \mathrm{~h}$ retirou-se uma placa de petri para a extração da enzima utilizando tampão fosfato de sódio $50 \mathrm{mM}$ pH 7,0 na proporção 1:5 (fermentado:tampão). Em seguida, foi realizada a pré-purificação da enzima com sulfato de amônio a $80 \%$.

A enzima parcialmente purificada foi imobilizada por ligação covalente segundo Santos (2014). O experimento consistiu em adicionar glutaraldeído $20 \%(\mathrm{v} / \mathrm{v})$ às membranas e deixar sob agitação à $120 \mathrm{rpm}, 30^{\circ} \mathrm{C}$ por $1 \mathrm{~h}$. Em seguida fez-se a filtração e lavagem das fibras com água destilada para remoção do excesso glutaraldeído. A solução enzimática ( $1 \mathrm{~mL}$ ) na concentração de $300 \mathrm{mg} / \mathrm{mL}$ foi misturada com $9 \mathrm{~mL}$ de hexano e $1 \mathrm{~g}$ de suporte, mantendo-se sob agitação durante $3 \mathrm{~h}$. Após este período, a solução foi mantida em repouso à temperatura de $4^{\circ} \mathrm{C}$ durante $24 \mathrm{~h}$. A enzima imobilizada foi recuperada por filtração à vácuo e lavada sucessivamente com hexano para remoção da lipase não adsorvida no suporte.

A atividade enzimática da lipase pré-purificada e do biocatalisador imobilizado (BI) foram determinados pelo método de hidrólise do azeite de oliva de acordo com o procedimento descrito por Soares et al. (1999), com algumas modificações.

$\mathrm{O}$ efeito do $\mathrm{pH}$ na atividade hidrolítica das lipases livre e imobilizada foi determinado pelo método de hidrólise do azeite de oliva utilizando o tampão citrato de sódio $0,1 \mathrm{M}$ nos pHs 2,0, 3,0, 4,0, e 5,0; tampão fosfato de sódio 0,1M nos pHs 6,0, 7,0, 8,0 e tampão carbonatobicarbonato de sódio $0,1 \mathrm{M}$ nos pHs 9,0, 10,0, 11,0.

\section{Produção de lipase}

\section{RESULTADOS E DISCUSSÃO}

A produção de lipase foi acompanhada ao longo do processo fermentativo conforme demonstrado na Fig. 1. A máxima atividade hidrolítica $244,98 \mathrm{U} / \mathrm{g}$ foi obtida quando utilizado umidade de resíduo de $70 \%$ em $168 \mathrm{~h}$ de fermentação. Este resultado foi superior aos obtidos por Santos et al. (2012) e Santos (2014), os quais produziram lipase de Aspergillus niger a partir de resíduo de abóbora (umidade de 30\%) e resíduo de mangaba (umidade de $30 \%$ ), respectivamente e obtiveram atividade máxima de 71,88 e $62,46 \mathrm{U} / \mathrm{g}$, respectivamente em $120 \mathrm{~h}$ de fermentação. 


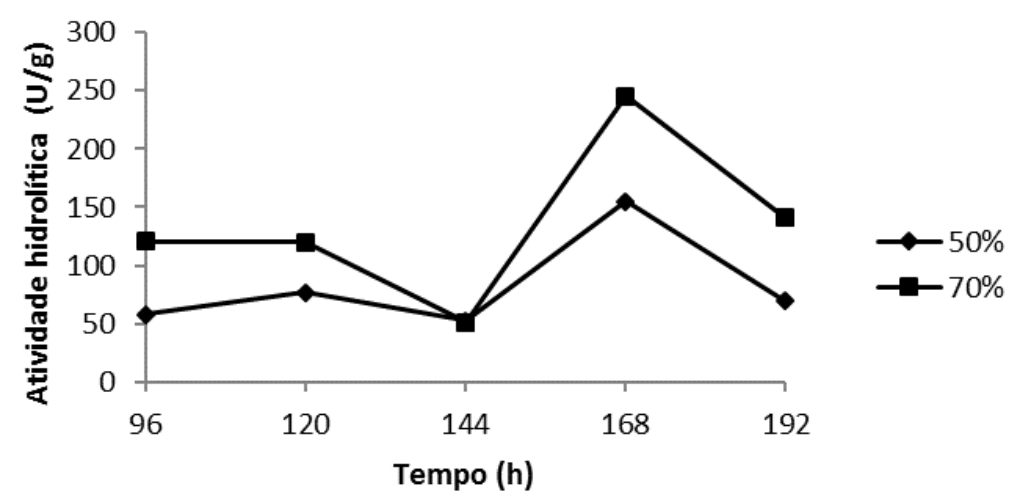

Fig 1. Produção de lipase ao longo do tempo de fermentação utilizando resíduo de mangaba com $50 \%$ e $70 \%$ de umidade

\section{Rendimento de imobilização e Efeito do pH}

A lipase foi imobilizada em membranas PES por ligação covalente obtendo-se rendimento de imobilização de $80 \%$. Em relação ao efeito pH observou-se que as lipases na forma livre e imobilizada apresentaram atividade relativa máxima (100\%) em pH 6,0. Santos (2014) tem obtido para a lipase de Aspergillus niger imobilizada em sol-gel por ligação covalente atividade relativa máxima em pH 3,0. Zubiolo et al. (2014) obtiveram máxima atividade relativa para a lipase de Aspergillus niger livre obtida de sementes de abóbora e imobilizada por encapsulação em matriz sol-gel de 4,0 e 3,0 respectivamente.

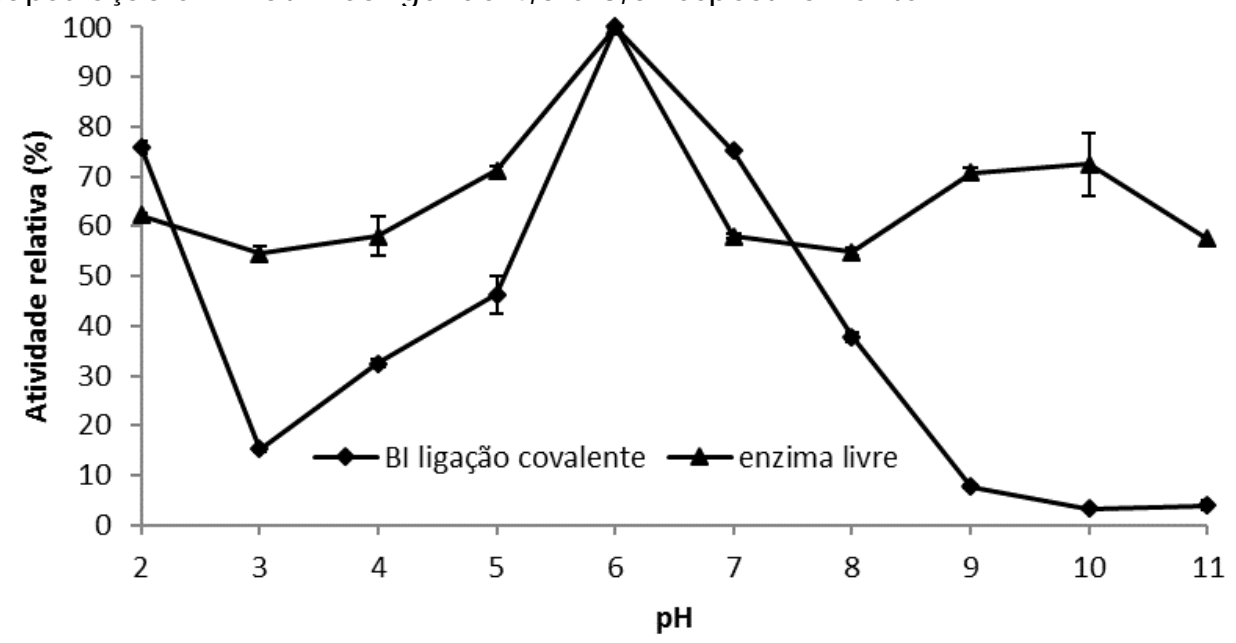

Fig 2. Efeito do pH na atividade da lipase na forma livre e imobilizada por ligação covalente

\section{CONCLUSÃO}

Lipase de Aspergillus niger foi produzida a partir da fermentação em estado sólido de resíduo de mangaba obtendo-se máxima atividade $(244,98 \mathrm{U} / \mathrm{g})$ quando utilizado resíduo contendo $70 \%$ de umidade em $168 \mathrm{~h}$ de fermentação. A enzima foi imobilizada eficientemente nas membranas de PES desde que o rendimento de imobilização foi de $80 \%$. Ambas enzimas na forma livre e imobilizada demonstraram pH ótimo de 6,0. 


\section{SIMPÓSIO DE BIOQUÍMICA E BIOTECNOLOGIA \\ 05 a 07 de agosto de 2015, Londrina - PR}

VSIMB:TEC

Londrina 2015

\section{REFERÊNCI AS}

BAYRAMOGLU, G; KAÇAR, Y; DENIZI, A.; ARICA, M.Y. Covalent immobilization of lipase onto hydrophobic group incorporated poly(2-hydroxyethyl methacrylate) based hydrophilic membrane matrix. J ournal of Food Engineering, v.52, p.367-374, 2002.

GUPTA, S.; YOGESH; JAVIYA, S.; BHAMBI, M.; PUNDIR, C. S.; SINGH, K.; BHATTACHARYA, A Comparative study of performances of lipase immobilized asymmetric polysulfone and polyether sulfone membranes in olive oil hydrolysis. International J ournal of Biological Macromolecules, v. 42, p. 145-151, 2008.

HUANG, X.J .; GE, D.; XU, ZK. Preparation and characterization of stable chitosan nanofibrous membrane for lipase immobilization. European Polymer J ournal, v. 43, p. 3710-3718, 2007.

LOOS, K; NASTASOV ' C, A; MILETI 'C, N. Immobilization of biocatalysts for enzimatic polymerizations: Possibilities, advantages, applications. Bioresource Technology, v.115, p. 126-135, 2011.

LU, P.; HSIEH, Y.L. Lipase bound cellulose nanofibrous membrane via Cibacron Blue F3GA affinity ligand. J ournal of Membrane Science, v. 330, p.288-296, 2009.

MATEO, C.; PALOMO, J.M.; FERNANDEZ-LORENTE, G.; GUISAN, J.M.; FERNANDEZ-LAFUENTE, R. Improvement of enzyme activity, stability and selectivity via immobilization techniques. Enzyme Mycrobiology technology 40,1451-1463, 2007.

MILETIC, N. , VUKOVI, Z, NASTASOVI, A., LOSS, K. I mmobilization of biocatalysts for enzymatic polymerizations: Possibilities, advantages, applications. Bioresource Technology, v.115, p. 126-135, 2012.

PUJARI N.S.; VAIDYA, B.K; BAGALKOTE, S.; PONRATHNAM, S.; NENEB, S. Poly(urethane methacrylate-coglycidylmethacrylate)-supported-polypropylene biphasic membrane for lipase immobilization. J ournal of Membrane Science, v. 285, p.395-403, 2006.

SANTOS, E.A.L. Lipase de Aspergillus niger obtida a partir da fermentação de resíduo de mangaba: potencial de imobilização em matriz sol-gel. Dissertação de mestrado- Universidade Federal de Sergipe, 2014.

SANTOS, R. C. A.; ARAÚJ O, K. B.; SOARES, C. M. F.; AQUINO, L. C. L. Evaluation of temperature and humidity response surface on the fermentation of lipase pumpkin seeds using Aspergillus niger. Acta Scientiarum Technology, v. 34, n. 3, p. 255-260, 2012.

SANTOS, R. C. A.; ARAÚJ O, K. B.; ZUBIOLO, C.; SOARES, C. M. F.; LMA, A. S. SANTANA, L.C.L.A Microbial lipase obtained from the fermentation of pumpkin seeds: immobilization potential of hydrophobic matrices. Acta Scientiarum. Technology, v. 36, n. 2, p. 193-201, 2014

SOARES, C. M. F.; CASTRO, H. F.; MORAES, F. F. de; ZANIN, G. M. Characterization and utilization of Candida rugosa lipase immobilized on controlled pore silica. Applied Biochemistry and Biotechnology, v. 77-79, p. 745-758, 1999.

WANG, Y.; HSIEH, Y.-L. Immobilization of lipase enzyme in polyvinyl alcohol (PVA) nanofibrous membranes. J ournal of Membrane Science, v. 309, p. 73-81, 2008.

VISHWANATH, S.; BHATTACHARYYA, D.; HUANG, W.; BACHAS, L. G. Site-directed and random enzyme immobilization on functionalized membranes: kietic studies and models. Journal of Membrane Science, v. 108, p. 1-13, 1995.

ZUBIOLO, C.; SANTOS, R. C. A; CARVALHO, N. B.; SOARES, C. M. F.; LIMA,. A. S.; SANTANA, L. C. L. A. Encapsulation in a sol-gel matrix of lipase from Aspergillus niger obtained by bioconversion of a novel agricultural residue. Bioprocess Biosystem Engineering, v.37, p. 1781-1788, 2014.

Universidade Estadual de Londrina - Rodovia Celso Garcia Cid, Pr 445, Km 380 - Campus Universitário Caixa Postal 10.011 CEP 86057-970 Centro de Ciências Exatas - Departamento de Bioquímica e Biotecnologia Fone +55 (43) 3371.4270 - biq@uel.br 